ORIGINAL ARTICLE

\title{
The Association between Changes in Coronary Artery Calcium Scores, Dietary Intake, Physical Activity, and Depression Symptoms among the Population of Gaza Strip, Palestine
}

\author{
Abdelrazeq Beram ${ }^{1}$, Kate Zinszer², Nouf bamuhair ${ }^{3,4}$, Samer Abuzerr ${ }^{5,6^{*}}$, Kamal \\ Jabre $^{7}$, Huda Gharbia ${ }^{7}$, Abdel Hamid el Bilbeisi ${ }^{8}$, Awny Ubeid ${ }^{7}$, Waliu Jawula \\ Salisu ${ }^{9}$
}

OPEN ACCESS

Citation: Abdelrazeq Beram, Kate Zinszer, Nouf bamuhair, Samer Abuzerr, Kamal Jabre, Huda Gharbia, Abdel Hamid el Bilbeisi Awny Ubeid, Waliu JawulaSalisu. The Association between Changes in Coronary Artery Calcium Scores, Dietary Intake, Physical Activity, and Depression Symptoms among the Population of Gaza Strip, Palestine. Ethiop J Health Sci. 2021;31(1):91 doi:http://dx.doi.org/ 10.4314/ejhs.v31i1.11 Received: August 7, 2020

Accepted: December 4, 2020

Published: January 1, 2021

Copyright: (C) 2021 Beram Abdelrazeq, et al. This is an open access article distributed under the terms of the Creative Commons Attribution License, which permits unrestricted use, distribution, and reproduction in any medium, provided the original author and source are credited.

Funding: Nil

Competing Interests: The authors declare that this manuscript was approved by all authors in its form and that no competing interest exists.

Affiliation and Correspondence:

${ }^{1}$ Prince Naeif Center for Radiodiagnostic, Ministry of Health, Gaza, Palestine

${ }^{2}$ School of Public Health, University of Montreal, Montréal, Canada

${ }^{3}$ University of the Science in the Philadelphia, Pennsylvania, U.S.A.

${ }^{4}$ Advanced Generation International

School, Jeddah, Saudi Arabia.

${ }^{5}$ Department of Social and Preventive

Medicine, University of Montreal,

Montréal, Canada

${ }^{5}$ Quality Improvement and Infection

Control Unit, Ministry of Health, Gaza, Palestine

${ }^{7}$ Department of Radiology, Al-Shifa Medical Complex, Ministry of Health, Gaza, Palestine

${ }^{8}$ Department of Clinical Nutrition, Al

Azhar University of Gaza, Palestine

${ }^{9}$ School of Nursing and Midwifery,

Tehran University of Medical Sciences

*Email: samer_516@hotmail.com

\section{ABSTRACT}

BACKGROUND: This study aimed to identify the association between macronutrient intake, physical activity, and depressive symptoms and changes in coronary artery calcium score among the population of Gaza Strip.

METHOD: The study sample consisted of 269 individuals who underwent non-enhanced coronary computed tomography using 64-slice MDCT (Siemens, Germany) at Al-Shifa medical complex between September 2017 and January 2018. The study participants were divided into two groups; group one, consisting of coronary calcium calcification scoring (CAC) of greater than zero (CAC score $>0)$, and group two, CAC less than or equal to zero (CAC score $\leq 0)$. Data about macronutrient intake, physical activity, and depressive symptoms were collected using a validated selfadministered questionnaire. Additionally, the participants' anthropometric characteristics and blood biochemical markers were measured.

RESULTS: Out of 269 participants, 45-recorded CAC score > 0; $72 \%$ of them were males with a mean age of $52.6 \pm 5.4$ years. Significant differences between the two groups in terms of total energy, lipid intake, and carbohydrate were found (P-value of $0.020,0.012$, and 0.034 , respectively). No significant differences were recorded in protein intake, physical activity, and depression. Multivariate logistic regression analysis under adjustment for possible confounding factors revealed that macronutrient intake, physical activity, and depressive symptoms were not associated with the development of CAC in two models. CONCLUSION: Based on our findings, macronutrient intake, physical activity, and depressive symptoms are not associated with the development of CAC among the population of Gaza.

KEYWORDS: Coronary artery calcium score, Depression, Dietary intake, Lifestyle, Strip, Physical activity 


\section{INTRODUCTION}

Ischemic heart disease is a significant cause of death worldwide. The World Health Organization (WHO) has estimated that more than 1 in 7 deaths that occurred in 2015 were caused by ischemic heart disease (1). Coronary artery disease (2) is caused by atherosclerosis of the coronary arteries that leads to a restriction of blood flow to the heart (3). Depending on the degree of stenosis and the characteristics of plaque, patients may experience stable angina or remain asymptomatic until a plaque ruptures and thrombosis occurs, causing acute coronary syndrome (4,5). Multidetector computed tomographic angiography (MDCTA) as a noninvasive examination is a valuable tool for the evaluation of carotid artery disease. It is used to detect early atherosclerotic changes within the carotid arteries, determine stenosis severity, identify the distribution and extent of atherosclerotic plaque, perform plaque characterization, and detect and characterize carotid dissections (6-8).

In recent years, there has been a considerable debate over the dietary intake and lifestyle habits of atherosclerosis. As has been emphasized in several previous studies, many socio-demographic and health-related variables have a direct relationship with developing CAC (9-12). Moreover, dietary intake has shown an association with cardiovascular calcification as high glucose and fat intake improve the plaque buildup inside the arteries $(13,14)$. It is worth mentioning that lifestyle behaviors such as oversleepiness $(15,16)$, lack of physical activity (17$19)$, and depression $(20,21)$ have been reported as leading causes of CAC. Contrary to this, earlier studies reported that macronutrient intake, physical activity, and depression are not associated with the development of coronary artery calcification $(22,23)$.

Therefore, our study aimed to identify the association between the development of atherosclerosis and macronutrient intake, physical activity, and depressive symptoms among the population of the Gaza Strip.

\section{METHODS}

Context of the study setting: The study was conducted at Al-Shifa medical complex which is located in the Gaza Strip, a setting suffering prolonged crises and experiencing persistent humanitarian situations. Difficulty accessing care, scarcities in resources, medications, insufficient health facilities, and staff capacity, tremendously challenging living circumstances, a disjointed healthcare system, and snowballing chronic diseases influence the health of people in the Gaza Strip (24-27).

Study design and population: The study population consisted of 269 individuals, (both genders, aged $\geq 18$ years), who underwent nonenhanced coronary computed tomography between September 2017 and January 2018. Pregnant women, lactating women, and patients with other types of serious illnesses such as cancer or end-stage kidney disease were excluded from the study.

Coronary Artery Calcification (CAC) measurement: Coronary artery calcification (CAC) was diagnosed using 64-slice MDCT (Siemens, Germany) at Al-Shifa medical complex. The facility, at the time of this study, was one of few health centers that provided nonenhanced coronary computed tomography in the Gaza Strip. Standard scanning protocol using 2.5-mm thickness without overlap and gap, $400 \mathrm{~ms}$ rotation time, $120 \mathrm{kV}$ tube voltage, and $124 \mathrm{mAs}(310 \mathrm{~mA} * 0.4 \mathrm{~s})$ tube current under ECG-gated dose modulation was followed. Coronary artery calcification was defined as more than three contiguous pixels above a CT density of 130 Hounsfield Units. The quantification of coronary artery calcium using ultrafast computed tomography was determined according to Agatston's method (28). The study participants were categorized into two groups; group one with CAC score $>0$ and group two with CAC score $\leq 0$.

Assessment of anthropometric measurements: Height was measured in all patients with a measuring rod attached to the balanced beam scale; the height was reported to the nearest 0.5 $\mathrm{cm}$. Weight ( $\mathrm{kg}$ ) was measured using a standard scale (Seca); the scale was placed on a hardfloor surface; patients were asked to remove their heavy outer garments, and weight was measured and recorded to the nearest $0.1 \mathrm{~kg}$. The Body Mass Index (BMI) was calculated by 
dividing weight in kilograms by the square of height in meters.

Blood biochemical markers: Blood samples were collected from the antecubital vein of each participant after 12 hours of fasting by registered nurses. Samples were directly sent to a licensed laboratory after collection in a Serum Separating Tube (SST). The extracted serum was analyzed for high-density lipoprotein cholesterol (HDL-c) $\mathrm{mg} / \mathrm{dl}$, low-density lipoprotein cholesterol (LDL-c) $\mathrm{mg} / \mathrm{dl}$, triglyceride (TGs) $\mathrm{mg} / \mathrm{dl}$, fasting serum glucose $(\mathrm{mg} / \mathrm{dL})$, total cholesterol $(\mathrm{mg} / \mathrm{dL})$, alanine aminotransferase (ALT), and gamma-glutamyl transferase (GGT). Additionally, LDL-c was calculated using the Friedwald formula; Mindray BS-300 chemistry analyzer instrument was used for blood chemistry analysis (29).

Dietary intake assessment: Data about dietary intake were collected by an expert nutritionist, using a validated semi-quantitative food frequency questionnaire (FFQ). The FFQ is relatively easy and inexpensive to administer and can be used to measure dietary intake over a prolonged period (29). The FFQ in our study contains a list of 98 food items; it was developed and validated among the Palestinian population in 2014 (30). All participants were asked to estimate the number of times per day, week, or month he/she consumed these particular food products and the amount usually eaten per food item by making comparisons with the specified reference portion. Everyday household items, including measuring cups, spoons, and a ruler, were shown to assist the participants in the estimation process. The answer categories ranged from 1 to 7 times ( 7 categories) including never, one to three times per month, one to two times per week, three to four times per week, five to six times per week, one time per day, or two to three times per day. The food composition of mixed dishes was determined by using traditional recipes consumed in the country. The mean intake of each food item in grams was calculated by multiplying the specified portion size by the average reported frequency. In addition, the USDA food composition tables were used to analyze nutrients consumption. Then, the participants were classified into four quartiles based on macronutrient intake $(\mathrm{Q} 1 \sim \mathrm{Q} 4)$.

Physical activity: Data on physical activity were obtained using the International Physical Activity Questionnaire (IPAQ short version) (31). The internationally accepted protocol was used to estimate the weekly calorie expenditure expressed as metabolic equivalents per week (MET/wk). The IPAQ scoring protocol assigns the following MET values to walk, moderate, and vigorous-intensity activity: 3.3 METs, 4.0 METs, and 8.0 METs, respectively (32).

Covariates assessment: A self-administered questionnaire was used to collect data about socioeconomic and demographic characteristics, past medical history, medication use, and healthrelated information of the study participants. A pilot study was carried out on twenty participants to enable the researchers to examine the tools of the study. The questionnaire and data collection process were modified according to the result of the pilot study.

Depression assessment: Depression was evaluated by the Center for Epidemiological Studies Depression Scale (CESD), which is a popular assessment tool that has broad applicability in the general population (33).

Blood pressure assessment (BP): The average of triplicate BP measurements was recorded using a stethoscope and mercury sphygmomanometer from the left arm $(\mathrm{mmHg})$. The participants were seated for fifteen minutes before the measurement in a quiet room without having any food, beverage, or smoke. The world health organizations' (WHO's) definition of high BP as a systolic BP equal to or above 140 $\mathrm{mmHg}$ and diastolic BP equal to or above 90 mmHg was adopted (34).

Ethical issues: The study was approved by the General Directorate of Human Resources Development in the Palestinian Ministry of Health. Moreover, written consent was obtained from each participant.

Statistical analyses: All statistical analyses were performed using statistical package for social science (SPSS) version 20. Normally distributed variables were presented as the mean $\pm \mathrm{SD}$, and skewed variables were presented as the median (interquartile range). Continuous variables were compared 
usingmindependent t-test between groups one and two (CAC score $>0$ and CAC score $\leq 0$ ). The multivariate logistic regression model was employed to identify Hazard Ratios (HRs) for the development of $\mathrm{CAC}$ with $95 \%$ confidence intervals (CIs) across the quartile of macronutrient intake, physical activity, and depression after adjustment of possible confounding factors. The lowest quartile group was considered as a reference. Two models were studied; the first model was adjusted for age and sex, and the second model for smoking, physical activity, glucose, TGs, HDL-c, LDL-c, BMI, and hypertension, which were considered statistically significant in the univariate logistic regression $(P$ values $<0.05)$.

\section{RESULTS}

Among 269 participants, 45 individuals had a CAC score $>0$. And, $72 \%$ of them were males with a mean age of $52.6 \pm 5.4$ years. Statistically significant associations were found between groups one and two. The individuals of group one were of older ages. They had higher BMI, systolic and diastolic BP, fasting serum glucose, lipid profiles levels, diabetes, hypertension, GGT, ALT, lower HDL-c and total energy ( $p$ values $<0.001)$. On the other hand, there were no statistically significant relationships between the two groups concerning smoking status, fat intake, carbohydrate intake, protein intake, physical activity, and depression status ( $p$ values $>0.05)$ (Table 1).

Table 1: Characteristics of the study participants according to coronary artery calcification

\begin{tabular}{|c|c|c|c|}
\hline \multirow[t]{2}{*}{ Variable } & \multicolumn{2}{|c|}{ CAC score } & \multirow{2}{*}{$\begin{array}{l}P \text { - } \\
\text { value }\end{array}$} \\
\hline & CAC score $\leq 0$ & CAC score $>0$ & \\
\hline Frequency $(\%)$ & $224(83.27)$ & $45(16.73)$ & - \\
\hline Male & $172(77)$ & $32(72)$ & 0.001 \\
\hline Age $(\text { years })^{\mathrm{a}}$ & $47.5(5.9)$ & $52.6(5.4)$ & 0.001 \\
\hline Smoking $(\%)$ & $81(36)$ & $17(38)$ & 0.367 \\
\hline Body mass index $\left(\mathrm{kg} / \mathrm{m}^{2}\right)^{\mathrm{a}}$ & $26.2(3.1)$ & $27.5(3.2)$ & 0.001 \\
\hline Systolic blood pressure $(\mathrm{mmHg})^{\mathrm{a}}$ & $119.5(12.4)$ & $122.4(12)$ & 0.001 \\
\hline Diastolic blood pressure $(\mathrm{mmHg})^{\mathrm{a}}$ & $76.3(9.6)$ & $78.9(9.7)$ & 0.001 \\
\hline Fasting serum glucose $(\mathrm{mg} / \mathrm{dl})^{\mathrm{a}}$ & $98.1(15.2)$ & $104.1(22.1)$ & 0.001 \\
\hline Total cholesterol $(\mathrm{mg} / \mathrm{dl})^{\mathrm{a}}$ & $206.9(36.5)$ & $218.8(38.1)$ & 0.001 \\
\hline Low-density lipoprotein-cholesterol $(\mathrm{mg} / \mathrm{dl})^{\mathrm{a}}$ & $130.3(32.9)$ & $141.5(34.4)$ & 0.001 \\
\hline Triglycerides $(\mathrm{mg} / \mathrm{dl})^{\mathrm{a}}$ & $135(143.3)$ & $161(168.5)$ & 0.001 \\
\hline $\begin{array}{l}\text { High-density lipoprotein-cholesterol } \\
(\mathrm{mg} / \mathrm{dl})^{\mathrm{a}}\end{array}$ & $51.5(12.3)$ & $49.1(11.0)$ & 0.001 \\
\hline Diabetes $(\%)$ & $20(9)$ & $9(19)$ & 0.001 \\
\hline Hypertension $(\%)$ & $43(19)$ & $13(29)$ & 0.001 \\
\hline Gamma glutamyl transferase $(\mathrm{U} / \mathrm{L})^{\mathrm{b}}$ & $36(24-55)$ & $41(28-67)$ & 0.001 \\
\hline Alanine aminotransferase $(\mathrm{U} / \mathrm{L})^{\mathrm{b}}$ & $26(19-38)$ & $30(22-41)$ & 0.001 \\
\hline Total energy (kcal per day) & $\begin{array}{l}1544.1(1162.0- \\
1820.0)\end{array}$ & $\begin{array}{l}1491.8(6484.2- \\
1662.7)\end{array}$ & 0.003 \\
\hline Fat $(\mathrm{g} \text { per day })^{\mathrm{b}}$ & $17.1(13.1-21.2)$ & $15.6(13.4-22.5)$ & 0.431 \\
\hline Carbohydrate (g per day) ${ }^{b}$ & $73.9(68.0-79.2)$ & $78.2(69.1-83.4)$ & 0.521 \\
\hline Protein (g per day) ${ }^{b}$ & $14.2(11.9-16.1)$ & $14.4(13.2-16.3)$ & 0.997 \\
\hline Physical activity (MET/week) ${ }^{b}$ & $997.7(447-1923)$ & $1162.8(545-2121)$ & 0.749 \\
\hline Depression (CES-D score) $)^{\mathrm{b}}$ & $5(1-10)$ & $5.5(1-11)$ & 0.495 \\
\hline
\end{tabular}

Abbreviations: (a) mean (standard deviation), (b) median (interquartile range), (\%) percentage, $(\mathrm{kg} / \mathrm{m} 2)$ Kilogram per square meter, $(\mathrm{mmHg})$ millimeter of mercury, $(\mathrm{mg} / \mathrm{dl})$ Milligrams per deciliter, $(\mathrm{U} / \mathrm{L})$ Units per liter, (MET) metabolic equivalent, and (CES-D) Center for Epidemiologic Studies Depression Scale 
The groups were compared based on quartiles of total energy intake, macronutrient intake, physical activity, and depression status. The results showed a statistically significant association with total energy, lipid, and
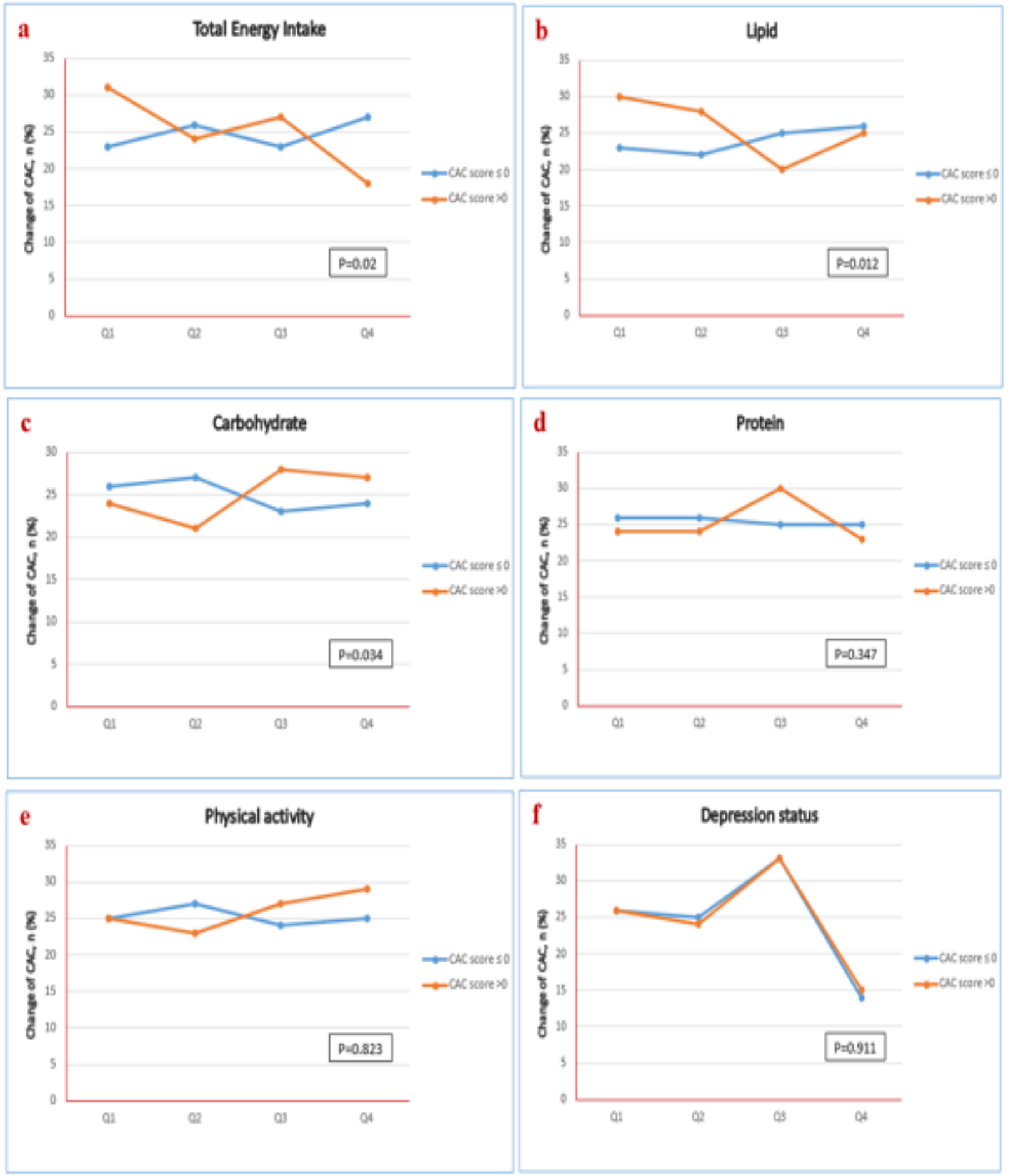

Figure 1: Correlation between CAC change and a) Total energy intake, b) Lipid intake, c) Carbohydrate intake, d) Protein intake, e) Physical activity, f) Depression status

DOI: http://dx.doi.org/10.4314/ejhs.v31i1.11

carbohydrate intake $(p$ values $=0.02,0.01,0.03$, respectively). Nevertheless, no statistically significant associations were found for protein intake, physical activity, and depression status ( $p$ values $>0.05$ ) (Figure 1).
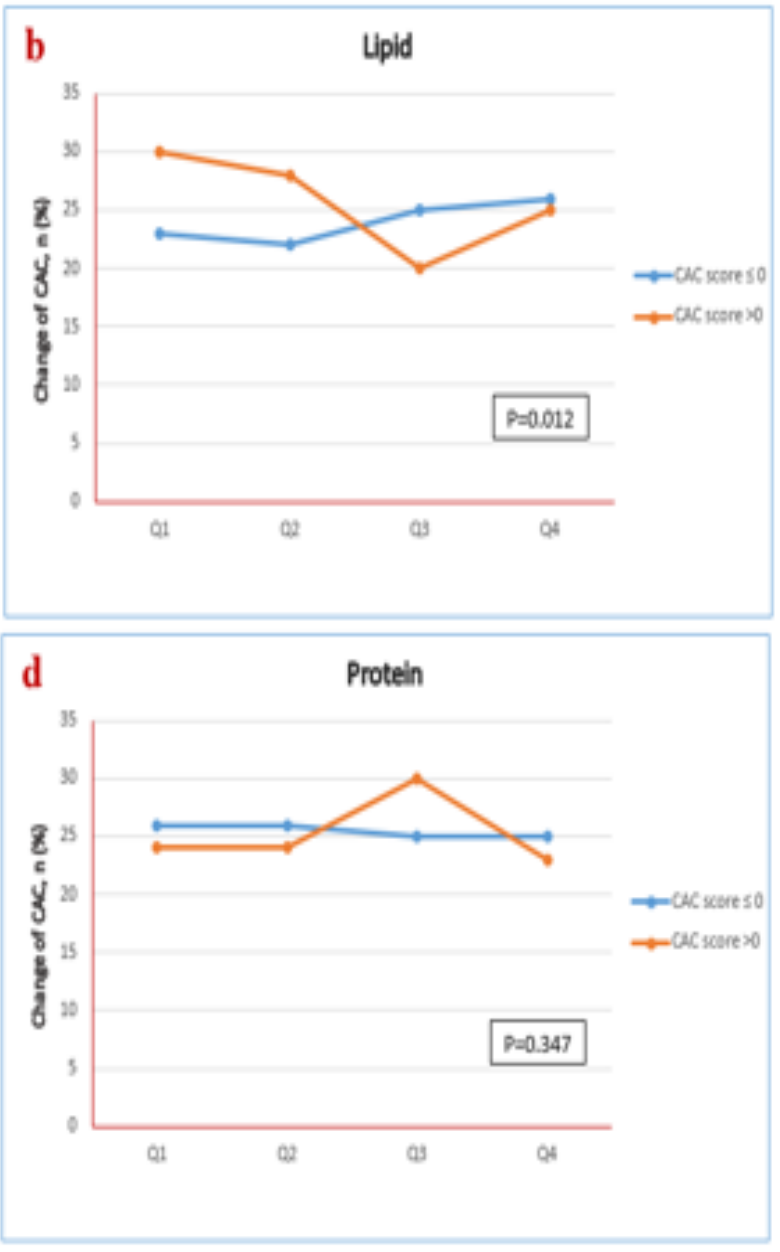
The multivariate logistic regression analysis was employed to assess the association between group one and quartile categories of macronutrient intake, physical activity, and depression. Two models were examined. The first model was adjusted for age and sex, whereas the second model was adjusted for smoking, physical activity, glucose, TGs, HDL- c, LDL-c, BMI, and hypertension. Even though several variables were significantly associated with CAC progression in univariate analyses, they all lost their significance in multivariable analysis while adjusting for potential confounders ( $\mathrm{p}$ values for trends $>0.05$ ) (Table 2).

Table 2: Multivariate logistic regression models for CAC score based on quartiles of macronutrients intake, physical activity, and depression.

\begin{tabular}{|c|c|c|c|c|c|}
\hline $\begin{array}{l}\text { Variable/CAC } \\
\text { change }>0\end{array}$ & Q1 & $\mathbf{Q 2}$ & Q3 & Q4 & $\begin{array}{l}P \text {-value } \\
\text { for } \\
\text { trend }\end{array}$ \\
\hline \multicolumn{6}{|l|}{ Total energy } \\
\hline $\mathrm{N}($ total $/ \mathrm{CAC}$ change $>0)$ & $68 / 12$ & $67 / 14$ & $67 / 10$ & $67 / 9$ & \\
\hline Model one & 1.00 & $0.780(.172-.486)$ & $0.377(.062-.950)$ & $0.754(0.383 .544)$ & 0.346 \\
\hline Model two & 1.00 & $0.822(.350-.560)$ & $0.097(.823-1.340)$ & $0.874(0.612-.487)$ & 0.422 \\
\hline \multicolumn{6}{|l|}{ Carbohydrate \% } \\
\hline $\mathrm{N}($ total $/$ CAC change $>0)$ & $68 / 13$ & $67 / 12$ & $67 / 10$ & $67 / 10$ & \\
\hline Model one & 1.00 & $0.780(.857-1.041)$ & $0.648(.341-.254)$ & $0.253(0.256 .580)$ & 0.611 \\
\hline Model two & 1.00 & $.522(.238-.760)$ & $0.855(.716-1.245)$ & $0.654(.711-2.051)$ & 0.247 \\
\hline \multicolumn{6}{|l|}{ Protein\% } \\
\hline $\mathrm{N}$ (total /CAC change $>0$ ) & $68 / 10$ & $67 / 16$ & $67 / 9$ & $67 / 10$ & \\
\hline Model one & 1.00 & $0.258(.631-1.166)$ & $0.875(.836-1.225)$ & $0.658(.813-1.021)$ & 0.645 \\
\hline Model two & 1.00 & $0.970(0.741-.950)$ & $0.395(.658-1.324)$ & $0.270(0.421-.660)$ & 0.983 \\
\hline \multicolumn{6}{|l|}{ Fat $\%$} \\
\hline $\mathrm{N}($ total $/ \mathrm{CAC}$ change $>0)$ & $68 / 12$ & $67 / 11$ & $67 / 8$ & $67 / 14$ & \\
\hline Model one & 1.00 & $0.142(.022-.366)$ & $0.342(.442-.842)$ & $0.457(.298-.870)$ & 0.163 \\
\hline Model two & 1.00 & $0.882(.734-1.110)$ & $0.748(.569-.732)$ & $0.745(.665-.892)$ & 0.146 \\
\hline \multicolumn{6}{|l|}{ Physical activity } \\
\hline $\mathrm{N}$ (total /CAC change $>0$ ) & $67 / 9$ & $67 / 13$ & $67 / 13$ & $67 / 10$ & \\
\hline Model one & 1.00 & $0.774(.258-1.311)$ & $0.474(.860-.899)$ & $0.621(.426-.897)$ & 0.578 \\
\hline Model two & 1.00 & $0.447(.232-1.241)$ & $0.841(.451-.660)$ & $0.832(.857-.938)$ & 0.135 \\
\hline \multicolumn{6}{|l|}{ Depression } \\
\hline $\mathrm{N}($ total $/ \mathrm{CAC}$ change $>0)$ & $68 / 12$ & $67 / 12$ & $67 / 10$ & $67 / 11$ & \\
\hline Model one & 1.00 & $0.763(.678-.844)$ & $0.216(.523-.364)$ & $0.680(.679-.356)$ & 0.228 \\
\hline Model two & 1.00 & $0.543(.567-.855)$ & $0.652(.413-.440$ & $0.450(.699-.930)$ & 0.238 \\
\hline
\end{tabular}

DOI: http://dx.doi.org/10.4314/ejhs.v31i1.11 


\section{DISCUSSION}

Our study showed that total energy intake, carbohydrate intake, protein intake, fat intake, physical activity, and depressive symptoms were not associated with the development of CAC after adjustment of possible confounding factors in the Gaza Strip.

Although recent studies have reported that excessive fat intake may accelerate the development of coronary vascular disease (CVD) (14), our findings were more compatible with the other earlier studies which suggest that dietary pattern and macronutrient intake may not be the leading causes of the atherosclerosis disease and carotid artery calcification after the adjustment for various confounders $(22,23,35)$.

Even though the BMI level among group one (CAC scores $>0$ ) was higher than group two (CAC score $\leq 0$ ), to no small extent, it can account for the weight loss due to the higher activity among the individuals of the second group. However, no significant relationship was achieved between the development of atherosclerosis and physical activity in this study. In contrast, many studies have indicated the importance of physical exercises in reducing the risk of atherosclerosis $(18,32,37)$.

Besides, an inverse relationship was found between the physical activity and incident of CAC. This was demonstrated in a multi-ethnic study (17).

Our results showed no association between the development of cardiovascular disease (CVD) and depression status. On the contrary, depressive symptoms have been consistently associated with a higher risk of coronary heart disease (CHD) $(20,21,38)$. Our result in this regard could be attributed to the variation in the sociocultural characteristics among the societies. As well, women seem to be more strongly affected by psychosocial stressors related to CVD and depression, and by direct/indirect effects of chronic stress compared to men (39). This seems to reflect in our findings as about 32 male participants had a CAC score $>0$.

Large-scale research in the future is recommended to confirm our results and to overcome the current shortcomings of this study, which are related to the small size of the study sample. Two CT scan machines that will provide non-enhanced coronary computed tomography are expected to be operational in the Gaza Strip soon. This will improve service delivery in the area and enable researchers to have access to more significant prospective participants for future studies.

In conclusion, our current findings indicate that the levels of macronutrient intake, physical activity, and depressive symptoms are not associated with CAC scores among the Palestinian population of the Gaza Strip. However, we recommend further research on a larger-scale in this area to confirm our findings.

\section{ACKNOWLEDGMENT}

The authors would like to thank and appreciate the staff of the Palestinian Ministry of Health and the study participants for their support.

\section{REFERENCES}

1. WHO. The top 10 causes of death, 2016. World Health Organization. 2017.

2. Gynecologists. AAoPatACoOa. Guidelines for perinatal care Washington DC2012.

3. Members TF, Montalescot G, Sechtem U, et al. 2013 ESC guidelines on the management of stable coronary artery disease: the Task Force on the management of stable coronary artery disease of the European Society of Cardiology. European heart journal. 2013;34(38):2949-3003.

4. ACS. American Cancer Society 2017.

5. Davies MJ. The pathophysiology of acute coronary syndromes. Heart. 2000;83(3):361-6.

6. Kuettner A, Kopp AF, Schroeder S, et al. Diagnostic accuracy of multidetector computed tomography coronary angiography in patients with angiographically proven coronary artery disease. Journal of the American College of Cardiology. 2004;43(5):831-9.

7. Budoff MJ, Dowe D, Jollis JG, et al. Diagnostic performance of 64-multidetector row coronary computed tomographic angiography for evaluation of coronary artery stenosis in individuals without known coronary artery disease: results from the 
prospective multicenter ACCURACY

(Assessment by Coronary Computed

Tomographic Angiography of Individuals

Undergoing Invasive Coronary

Angiography) trial. Journal of the American

College of Cardiology. 2008;52(21):1724-

32.

8. Budoff M, Dowe D, Jollis J. diagnostic performance of 64-multidetector row coronary computed tomographic angiography for evaluation of coronary artery stenosis in individuals without known coronary artery disease: results from the Prospective Multicenter Accuracy (assessment by Coronary Computed Tomographic Angiography of Individuals Undergoing Invasive Coronary Angiography) Trial. Journal of Vascular and Interventional Radiology. 2009;20(3):429.

9. Cassidy-Bushrow AE, Bielak LF, Sheedy 2nd $\mathrm{P}$, et al. Coronary artery calcification progression is heritable. Circulation. 2007;116(1):25-31.

10. Kramer CK, Von MÜhlen D, Gross JL, Laughlin GA, Barrett-Connor E. Blood pressure and fasting plasma glucose rather than metabolic syndrome predict coronary artery calcium progression: the Rancho Bernardo Study. Diabetes care. 2009;32(1):141-6.

11. Elkeles RS, Godsland IF, Rubens MB, Feher MD, Nugara F, Flather MD. The progress of coronary heart disease in type 2 diabetes as measured by coronary calcium score from electron beam computed tomography (EBCT): the PREDICT study. Atherosclerosis. 2008;197(2):777-83.

12. Kronmal RA, McClelland RL, Detrano R, et al. Clinical Perspective. Circulation. 2007;115(21):2722-30.

13. Liu F, Zhong H, Liang J-y, et al. Effect of high glucose levels on the calcification of vascular smooth muscle cells by inducing osteoblastic differentiation and intracellular calcium deposition via BMP-2/Cbfo-1 pathway. Journal of Zhejiang University SCIENCE B. 2010;11(12):905-11.
14. Brunner E, Rees K, Ward K, Burke M, Thorogood M. Dietary advice for reducing cardiovascular risk. Cochrane Database of Systematic Reviews. 2007(4).

15. Abe T, Aoki T, Yata S, Okada M. Sleep duration is significantly associated with carotid artery atherosclerosis incidence in a Japanese population. Atherosclerosis. 2011;217(2):509-13.

16. Ma CC, Burchfiel CM, Charles LE, et al. Associations of objectively measured and self-reported sleep duration with carotid artery intima media thickness among police officers. American journal of industrial medicine. 2013;56(11):1341-51.

17. Delaney JA, Jensky NE, Criqui MH, WhittGlover MC, Lima JA, Allison MA. The association between physical activity and both incident coronary artery calcification and ankle brachial index progression: the multi-ethnic study of atherosclerosis. Atherosclerosis. 2013;230(2):278-83.

18. Kwaśniewska M, Jegier A, Kostka T, et al. Long-term effect of different physical activity levels on subclinical atherosclerosis in middle-aged men: a 25 -year prospective study. PloS one. 2014;9(1):e85209.

19. Ried-Larsen M, Grøntved A, Kristensen PL, Froberg K, Andersen LB. Moderate-andvigorous physical activity from adolescence to adulthood and subclinical atherosclerosis in adulthood: prospective observations from the European Youth Heart Study. $\mathrm{Br} J$ Sports Med.2015;49(2):107-12.

20. Hamer M, Kivimaki M, Lahiri A, Marmot MG, Steptoe A. Persistent cognitive depressive symptoms are associated with coronary artery calcification. Atherosclerosis. 2010;210(1):209-13.

21. Rozanski A, Blumenthal JA, Davidson KW, Saab PG, Kubzansky L. The epidemiology, pathophysiology, and management of psychosocial risk factors in cardiac practice: the emerging field of behavioral cardiology. Journal of the american college of cardiology. 2005;45(5):637-51. 
22. Sung K-C, Sung E, Byrne CD, Kim YB, Ahn CW, Chung H-K. Composition of dietary macronutrient intake is not associated with prevalence of coronary artery calcification in healthy Korean adults. Annals of Nutrition and Metabolism. 2015;66(1):36-43.

23. Cheong E, Lee J-Y, Lee SH, et al. Lifestyle including dietary habits and changes in coronary artery calcium score: a retrospective cohort study. Clinical hypertension. 2015;22(1):5.

24. AlKhaldi M, Abuzerr S, Obaid H, Alnajjar G., Alkhaldi A, Khayyat A. Social Determinants of Health in Fragile and Conflict Settings: The Case of the Gaza Strip, Palestine. In: Laher I. (eds) Handbook of Healthcare in the Arab World. Springer, Cham. 2020.

25. Abuzerr S, Hadi M, Zinszer $K$, et al. Comprehensive Risk Assessment of HealthRelated Hazardous Events in the Drinking Water Supply System from Source to Tap in Gaza Strip, Palestine. Journal of Environmental and Public Health. 2020.

26. Abuzerr S, Nasseri S, Yunesian $M$, et al. Water, sanitation, and hygiene risk factors of acute diarrhea among children under five years in the Gaza Strip. Journal of Water, Sanitation and Hygiene for Development. 2020; (1):111-123.

27. Abuzerr S, Nasseri S, Yunesian $M$, et al. Prevalence of diarrheal illness and healthcare-seeking behavior by age-group and sex among the population of Gaza strip: a community-based cross-sectional study. BMC public health. 2019; 19(1):704.

28. Agatston AS, Janowitz WR, Hildner FJ, Zusmer NR, Viamonte M, Detrano R. Quantification of coronary artery calcium using ultrafast computed tomography. Journal of the American College of ardiology. 1990;15(4):827-32.

29. el Bilbeisi AH, Hosseini S, Djafarian K. Association of dietary patterns with diabetes complications among type 2 diabetes patients in Gaza Strip, Palestine: a cross sectional study. Journal of Health, Population and Nutrition. 2017;36(1):37.
30. Hamdan M, Monteagudo C, Lorenzo-Tovar M-L, Tur J-A, Olea-Serrano F, MariscalArcas M. Development and validation of a nutritional questionnaire for the Palestine population. Public health nutrition. 2014;17(11):2512-8.

31. Craig CL, Marshall AL, Sjöström M, Bauman AE, Booth ML, Ainsworth BE, et al. International physical activity questionnaire: 12-country reliability and validity. Medicine \& science in sports \& exercise. 2003;35(8):1381-95.

32. el Bilbeisi AHH, Albelbeisi A, Hosseini S, Djafarian K. Dietary Pattern and Their Association With Level of Asthma Control Among Patients With Asthma at Al-Shifa Medical Complex in Gaza Strip, Palestine. Nutrition and metabolic insights. 2019;12:1178638819841394.

33. Van Dam NT, Earleywine M. Validation of the Center for Epidemiologic Studies Depression Scale-Revised (CESD-R): Pragmatic depression assessment in the general population. Psychiatry research. 2011;186(1):128-32.

34. WHO. Raised blood pressure. Global Health Observatory data. World Health Organization. 2017( Accessed 1 December 2017).

35. Nettleton JA, Schulze MB, Jiang R, Jenny NS, Burke GL, Jacobs Jr DR. A prioridefined dietary patterns and markers of cardiovascular disease risk in the MultiEthnic Study of Atherosclerosis (MESA). The American journal of clinical nutrition. 2008;88(1):185-94.

36. Matos-Souza JR, Silva AA, Campos LF, et al. Physical activity is associated with improved subclinical atherosclerosis in spinal cord injury subjects independent of variation in traditional risk factors. International journal of cardiology. 2013;167(2):592-3. 
37. Astengo M, Dahl Å, Karlsson T, MattssonHultén L, Wiklund $\mathrm{O}$, Wennerblom B. Physical training after percutaneous coronary intervention in patients with stable angina: effects on working capacity, metabolism, and markers of inflammation. European Journal of Cardiovascular Prevention \& Rehabilitation. 2010;17(3):349-54.

38. Nicholson A, Kuper H, Hemingway $H$. Depression as an aetiologic and prognostic factor in coronary heart disease: a metaanalysis of 6362 events among 146538 participants in 54 observational studies. European heart journal. 2006;27(23):276374.

39. Moeller-Leimkuehler AM. Higher comorbidity of depression and cardiovascular disease in women: a biopsychosocial perspective. The world journal of biological psychiatry. 2010;11(8):922-33. 